\title{
A FORMAÇÃO DO PROFESSOR UNIVERSITÁRIO NO PERCURSO DE PÓS-GRADUAÇÃO EM QUÍMICA
}

\author{
University teachers' training \\ in the Post-graduate Degree Programs in Chemistry
}

\author{
Ana Luiza de Quadros ${ }^{1}$. Dayse Carvalho da Silva² • Fernando César \\ Silva $^{3}$. Frank Pereira de Andrade ${ }^{4}$. Helga Gabriela Aleme ${ }^{4}$. Sheila \\ Rodrigues Oliveira ${ }^{6}$. Gilson de Freitas Silva ${ }^{7}$ Juliana Cristina \\ Tristão ${ }^{8}$ Leandro José dos Santos ${ }^{9}$
}

\begin{abstract}
Resumo: Nos últimos anos, o olhar de educadores/pesquisadores brasileiros tem se voltado para a formação didática do professor de Ensino Superior. Seguindo esta tendência, investigamos a percepção dos estudantes do Programa de Pós-graduação em Química da Universidade Federal de Minas Gerais sobre a preparação para a docência, tanto no que vivenciam no curso como no que consideram importante como preparação para a docência no Ensino Superior. Percebemos que os estudantes sentem e expressam a necessidade da formação docente, mesmo com interesses nem sempre convergentes com uma boa preparação didático-pedagógica. As iniciativas oferecidas no programa em questão, a partir da última década, vêm ao encontro das necessidades descritas pelos pesquisados, mas precisam ser ampliadas, num processo amplamente reflexivo.
\end{abstract}

Palavras-chave: Pós-graduação. Ensino de química. Ensino Superior. Formação pedagógica.

\begin{abstract}
The didactic training in higher education of Brazilian teachers' has received more attention in recent years. Therefore, we investigate students' perceptions from the Post-graduate Degree Program in Chemistry at the Federal University of Minas Gerais. Thus, we recognize that these students don't feel prepared and express their need for a didactic training, as they are without any pedagogical preparation. The initiatives offered in the program in question, in the last decade, recognize the students' needs, but they have to be extended into a reflective process.
\end{abstract}

Keywords: Post-graduate. Chemistry teaching. Higher Education. Didactic training.

${ }^{1-6}$ Departamento de Química, Instituto de Ciências Exatas, Universidade Federal de Minas Gerais (UFMG). Belo Horizonte, MG, Brasil.

${ }^{7}$ Departamento de Química Geral e Inorgânica, Universidade Federal da Bahia (UFBA). Salvador, BA, Brasil.

${ }^{8,9}$ Universidade Federal de Viçosa (UFV), Campus de Florestal. Rodovia LMG, 818, km 6. Florestal, MG, Brasil. 35.690-000. leandroj.santos@ufv.br 
Quadros, A. L. et al.

\section{Introdução}

A sala de aula é um espaço/tempo privilegiado para que a aprendizagem aconteça como decorrência de um planejamento criterioso e do uso de estratégias diversificadas, que promovam um confronto de ideias e a "negociação" de significados. Nela se reúnem estudantes e professor, para adentrar no conhecimento específico que estrutura a aula e permite entender o mundo do ponto de vista da ciência. Este ambiente pode, assim, ser definido como um espaço/tempo de relações: entre estudantes, de estudantes e professor, e de ambos com o conhecimento.

Certamente, o professor é um personagem em destaque na sala de aula, por ser o especialista naquele campo do saber, com conhecimentos específicos superiores aos demais, e por ser o "gerenciador" daquele ambiente. $\mathrm{Na}$ universidade, o professor tem, como uma das principais atividades, ministrar aulas em determinadas disciplinas. Desta maneira, ele se torna responsável pelo gerenciamento das salas de aula, nas quais vai, juntamente com os estudantes, navegar pelo campo do saber no qual se especializou. Contudo, entre estudantes de graduação, são comuns comentários referentes à didática do professor, uma vez que a mesma se dá pela exposição de conteúdo, pela leitura de fragmentos de textos ou por seminários (ARROIO; RODRIGUES FILHO; SILVA, 2006).

Apesar da incontestável titulação acadêmica, são comuns relatos de estudantes sobre professores que dominam o conteúdo, mas têm dificuldades de ensiná-lo e/ou transmiti-lo e, assim, não conseguem conduzir uma aula, atuando, algumas vezes, de forma arrogante e, ainda, mostrando-se mais interessados em seus trabalhos de pesquisa, em detrimento da atividade docente (PACHANE, 2007).

Uma possível explicação para tais situações pode estar relacionada às exigências, presentes nos editais de concurso público, para o ingresso de professores nas instituições públicas de Ensino Superior. Nesses processos seletivos, valorizam-se, na maioria das vezes, a produção científica dos candidatos e o conhecimento relativo ao campo de saber ao qual concorrem, em detrimento do campo pedagógico e suas relações com as disciplinas técnico-científicas, mesmo que a vaga seja para um docente-pesquisador. $\mathrm{O}$ fato de um professor de graduação de áreas específicas do conhecimento, como é o caso da Química, se afastar do campo pedagógico, dificulta a prática de ensino (ARROIO; RODRIGUES FILHO; SILVA, 2006).

A pouca inserção de professores universitários dos cursos de formação mais técnica no campo pedagógico é devido, sobretudo, à formação nos programas de pós-graduação. Nestes, o estudante desenvolve sua pesquisa e constrói seu currículo alicerçado na produção científica (maior número de artigos publicados, trabalhos em congressos, publicação/orientação de teses, patentes etc.), em detrimento de qualquer estudo que auxilie na formação didática. Assim, os novos professores, mesmo os graduados em licenciatura, desenvolverão seu trabalho da mesma maneira que vivenciaram em toda sua trajetória. Considerando que, como estudantes, tiveram aulas baseadas no modelo de transmissão/recepção de conhecimento, e supondo ter sido este um modelo eficiente, tendem a ministrar suas aulas da mesma maneira (MALDANER, 1999). Na pesquisa realizada por Maldaner (1999, p. 290), um dos professores pesquisados, ao ser questionado sobre o trabalho que realizava em sala de aula, responde que "Eu aprendi assim, porque haveria de ser diferente com meu aluno?"

A formação em programas de pós-graduação (PPG) strictu sensu é considerada como requisito básico para atuarem como professores nas universidades. Esta é uma das recomen- 
A formação do professor universitário ...

dações presentes na Lei de Diretrizes e Bases da Educação Nacional, Lei nº. 9394 de 21/12/ 1996, mais especificamente no Art. 66 (BRASIL, 1996). Contudo, o título de mestre e doutor não garante a orientação pedagógica para a prática docente (ARROIO; RODRIGUES FILHO; SILVA, 2006), e toda ideia de que estas titulações capacitam, de maneira automática, para a docência é amplamente questionada (PACHANE, 2007). Segundo Pachane (2007) palestras, cursos e oficinas são sugeridos como meio de reverter este quadro, mas com resultados nem sempre significativos. Em seu trabalho, a autora avaliou a participação de estudantes em um Programa de Estágio e Capacitação Docente (PECD-Unicamp), nos anos de 1993 a 2000, e relatou um aumento no comprometimento dos professores iniciantes e veteranos no que diz respeito a questões educacionais.

Algumas alternativas (ZANON; OLIVEIRA; QUEIROZ, 2009; ARROIO et al., 2008; FEITOSA, 2002; FELICÍSSIMO et al., 1991) já foram desenvolvidas para oferecer, aos discentes de pós-graduação, a oportunidade de desenvolverem e/ou aprimorarem sua prática docente. Elas surgiram, sobretudo, após a Coordenação de Aperfeiçoamento de Pessoal de Nível Superior (CAPES) incorporar em seu estatuto, a partir de 1999, o Estágio Supervisionado em Docência como elemento integrante da formação do pós-graduando. Arroio et al. (2008) afirmam que a vivência dos estudantes em atividades docentes é bastante relevante, pois desperta seu espírito crítico e reflexivo por meio de suas próprias experiências.

Considerando que as discussões acerca da formação do professor do Ensino Superior têm recebido atenção de pesquisadores nacionais nos últimos anos, este trabalho tem como objetivo verificar as principais práticas docentes vivenciadas pelos estudantes no percurso da formação no Programa de Pós-Graduação (PPG) em Química da Universidade Federal de Minas Gerais. Além disto, buscamos entender como as oportunidades oferecidas pelo PPG atendem às necessidades formativas dos pós-graduandos, caso estes venham a atuar como professores.

\section{Metodologia}

\section{Construindo o caminho}

Para encontrarmos evidências que permitissem argumentar sobre a formação didática de estudantes do PPG em Química da Universidade Federal de Minas Gerais (UFMG), elaboramos um instrumento de coleta de dados, na forma de questionário. Este visava compreender dois aspectos principais: o primeiro se refere às perspectivas dos estudantes de pósgraduação com o mercado de trabalho ao findarem suas pesquisas; e o segundo, com a experiência docente no decorrer do curso de pós-graduação. Este último aspecto foi avaliado sob três perspectivas: as atividades vivenciadas pelos estudantes, as possibilidades que vislumbram para vivenciar a experiência docente, e as necessidades que sentem em relação à formação para a docência.

O questionário foi entregue a 166 estudantes do PPG em Química da UFMG, matriculados no segundo semestre de 2009. Destes, recebemos o retorno de 99 estudantes (67 doutorandos, 31 mestrandos e um que não informou o nível de estudo) que tiveram o tempo de até uma semana para responder às perguntas. 
Quadros, A. L. et al.

\section{Situando o contexto}

A UFMG oferece 67 pós-graduações, que envolvem cursos de mestrado, mestrado profissional e doutorado em diversas áreas do conhecimento. Dentre estes está a pós-graduação strictu sensu em química, classificada entre as melhores do país. Na avaliação feita em 2007 pela CAPES, o programa obteve nota seis (em uma escala na qual a nota máxima é sete). Dentre os objetivos do PPG em Química da UFMG, está a formação de pessoal qualificado para o exercício de atividades profissionais de pesquisa e de ensino de nível Superior (UNIVERSIDADE FEDERAL DE MINAS GERAIS, 2010).

Na grade curricular do PPG em Química da UFMG, são ofertadas cerca de 30 disciplinas. Destas, apenas o Treinamento em Docência em Química, com 60 horas aula, optativa desde 1999 e obrigatória a partir de 2009, está diretamente relacionada à formação didática para a docência. Nela os estudantes de mestrado e doutorado têm a oportunidade de vivenciar o ambiente de sala de aula como docente, durante até dois semestres letivos, sob a supervisão de um professor-orientador.

\section{Resultados e discussão}

\section{A perspectiva quanto ao campo de trabalho}

Em trabalho realizado anteriormente (QUADROS et al., 2011), observamos que muitos dos estudantes do PPG em Química da UFMG têm, como perspectiva de atuação profissional, a prática docente. Ao serem convidados a se imaginar no mundo de trabalho, as opções oferecidas foram de atividades ligadas à pesquisa, ao ensino ou a ambos. As respostas obtidas encontram-se na Tabela 1.

\begin{tabular}{lc} 
Tabela 1. A visão dos estudantes do PPG em Química \\
quanto à atuação no mercado de trabalho futuro \\
\hline \multicolumn{1}{c}{ Atuação Profissional } & Número de respostas \\
\hline Professor e pesquisador & 70 \\
Pesquisador & 14 \\
Professor & 13 \\
Outro & 01 \\
Total & 99 \\
\hline
\end{tabular}

Fonte: Quadros et al. (2011).

Observamos que ser professor não faz parte do imaginário de apenas 15 deles (segunda e quarta categorias da Tabela 1). Destes, 14 afirmaram que serão pesquisadores, e um, que irá trabalhar como perito em investigações criminais. Todos os demais, de alguma forma, imaginam-se professores, sendo que 13 deles desenvolvendo apenas esta função e setenta dividindo as tarefas entre professor e pesquisador. Esta percepção nos faz argumentar que, apesar de estarem inseridos em um PPG em Química que não tem ligação direta com a 
A formação do professor universitário ...

preparação didático-pedagógica de professores, ser professor é uma possibilidade vislumbrada por muitos deles.

\section{O estágio supervisionado em docência dos PPG}

A Capes, um dos principais órgãos de regulamentação e fomento dos cursos de pósgraduação do país, revelou atenção com a formação didática ao determinar, a partir de 1999, a obrigatoriedade do Estágio em Docência para os seus bolsistas, ministrando aulas na graduação. Trata-se de um treinamento que visa o desenvolvimento dos estudantes em termos de habilidades didáticas, tendo em vista que estes programas habilitam profissionais para as áreas de pesquisa e para o Ensino Superior. Assim, a maioria dos PPG passou a ofertar, a partir de 2000, uma disciplina de treinamento em docência que abrange aspectos didáticos teóricos e práticos, com o intuito de cumprir a determinação da Capes.

No PPG em Química da UFMG, a disciplina Treinamento em Docência em Química é oferecida desde 1999. Nela o estudante desempenha atividades de ensino com supervisão, em uma ou mais disciplinas dos cursos de graduação. Este treinamento, geralmente, é desenvolvido em fases distintas. Inicialmente, o pós-graduando passa pela fase de observação, acompanhando as aulas ministradas pelo professor orientador, e, posteriormente, atua na execução/elaboração de atividades na forma de aulas, seminários, provas e exercícios.

A disciplina Treinamento em Docência em Química é a única com estreita ligação com o ensinar e aprender presente dentro do programa. Desta forma, procuramos identificar quantos estudantes tiveram a oportunidade e interesse em cursá-la. Para os que a cursaram, investigamos se eles se sentem preparados ou não para ministrarem as aulas.

Dos 99 discentes que responderam a esta pergunta, oitenta ainda não cursaram a disciplina Treinamento em Docência. Isto significa que ela pode estar sendo cursada apenas pelos estudantes que assumiram este compromisso junto à Capes, já que ela só foi objeto de interesse de cerca de $20 \%$ deles. A partir de 2009, ela passou a fazer parte do conjunto de disciplinas obrigatórias para todos os doutorandos ingressantes no programa e, por isto, a participação aumentará.

O pouco interesse dos pós-graduandos pela única disciplina que tem ligação com o ensinar e aprender está vinculado a um entendimento arcaico relativo às necessidades para a formação do professor. A história da educação brasileira nos mostra que o exercício docente era visto como vocação, exigindo que o interessado detivesse um pouco mais de conhecimento para se transformar em um professor. Porém, estas exigências de outrora não são as mesmas da contemporaneidade, e não teriam como sê-las, diante dos avanços técnicos e científicos atuais (MEDEIROS, 2007).

Para os 19 estudantes que passaram pela disciplina, investigamos como se deu a preparação para assumir o conjunto de aulas relativas ao estágio. Destes, sete afirmaram ter recebido assistência, por parte dos professores responsáveis pela disciplina, na revisão do conteúdo e na organização dos tópicos ministrados durante o treinamento. Três apenas acompanharam as aulas dos professores das disciplinas, para se prepararem para ministrar os conteúdos abordados, e seis afirmaram ter se preparado sozinhos para as aulas. Outras respostas foram: preparo das aulas por apostilas (uma), com materiais da própria graduação (uma) e não teve muita preparação (uma). 
Quadros, A. L. et al.

Foi possível constatar que a orientação que estes estudantes recebem ao assumir a sala de aula, como professores, é mais voltada ao conteúdo do que a aspectos didático-pedagógicos. O fato do PPG em Química não ter linhas de pesquisa ligadas a questões de educação química mostra que a orientação, quando existe, é de professores cuja formação não envolveu, necessariamente, teorias de ensino e aprendizagem. Portanto, a orientação fornecida é coerente com a formação dos formadores que lá atuam. Parece-nos que não tem havido, na universidade como um todo, uma reflexão mais sistemática sobre o tipo de orientação didáticopedagógica necessária e/ou relevante na preparação de futuros professores universitários.

Não seria esperado, de programas que não têm qualquer tradição com a formação didático-pedagógica de docentes, iniciá-la de forma exemplar. Porém, uma parceria com outros programas, especialmente da área de educação, poderia trazer resultados mais expressivos em termos de formação docente. Os professores que fazem parte destes programas possuem uma experiência considerável na preparação de aulas, já que isto faz parte do seu trabalho. Porém, ao orientarem no planejamento de aulas, poderão estar consolidando práticas que já copiaram dos professores que tiveram e que serão, agora, copiadas pelos seus próprios estudantes.

Vimos que, entre os poucos estudantes que adentraram no Treinamento em Docência, nem todos foram auxiliados pelos professores. Um número significativo de estudantes afirma ter administrado sozinho o planejamento e a execução das aulas. Além de comprometer a qualidade das aulas, o despreparo também pode reforçar uma concepção existente de que, para dar aulas, basta saber o conteúdo específico. Consideramos importante que, na formação para a docência, sejam levados em conta o planejamento, a reflexão, a avaliação e o replanejamento de ações, num processo, chamado por Schön (1992), de conhecimento na ação (saber escolar que é mobilizado na ação), reflexão na ação (observações e reflexões sobre o modo como o professor desenvolve sua prática docente) e ação sobre a reflexão na ação (ação passada projetando novas práticas).

A inserção dos estudantes em sala de aula, assumindo o papel de professores, certamente não será suficiente para prepará-los para a docência se este não for um processo refletido. Conhecer o conteúdo é condição necessária para atuar adequadamente como professor, apesar de não ser condição única. A formação docente é uma construção epistemológica e profissional, que considera os conhecimentos específicos da área de saber, os didático-pedagógicos e os da experiência, entrecruzando-se.

Segundo Medeiros (2007), a docência demanda um conjunto de quatro saberes que incluem: a) interdisciplinaridade; b) conteúdos didático-pedagógicos diretamente relacionados ao campo da prática profissional; c) conteúdos relacionados a saberes pedagógicos mais amplos do campo teórico da prática educacional, e d) conteúdos ligados à explicitação de sentido da existência humana individual, com sensibilidade pessoal e social. São saberes que extrapolam o conhecimento específico da área na qual atuam os professores de Química do Ensino Superior. Sabemos que a universidade insere a prática de ensino e os estágios curriculares na grade curricular de todos os seus cursos de formação de professores. Nestes componentes curriculares - estágio e prática de ensino - estão presentes saberes considerados importantes para que o professor desempenhe o seu trabalho de forma a produzir aprendizagens, como os citados por Medeiros (2007). Porém, ao que parece, a universidade considera desnecessários estes saberes a seus próprios professores. 
A formação do professor universitário ...

\section{Vivências e possibilidades que vislumbram para a formação docente}

Solicitamos que os estudantes descrevessem as atividades, desenvolvidas dentro do PPG, que podem auxiliar na preparação para a docência, caso eles venham a assumir o papel de professores, ao adentrarem no mundo profissional. Por meio da análise dos dados coletados, foi possível constatar o baixo grau de informação dos estudantes do PPG a respeito da formação docente. Uma grande parcela dos 99 estudantes pesquisados (36) afirmou não ter conhecimento de qualquer atividade que auxilie na formação didática de docentes dentro do programa; 22 deles conhecem o Estágio de Docência; dois relataram ter tido a oportunidade de atuarem como professor substituto, e um, que atuou como professor voluntário. Outros dois consideraram que o auxílio para a formação do docente está no conhecimento químico que adquirem no curso. Dos pesquisados, 36 não responderam a esta questão.

Diante deste resultado, podemos afirmar que grande parte dos pós-graduandos dirige a atenção para a formação específica e, por isto, não procuram saber a respeito das oportunidades oferecidas pelo PPG. Considerando a formação dos professores que fazem parte do PPG em Química, esta parece ser a lógica de pensamento: por que a formação didática se todos desempenham suas atividades sem esta formação?

Concordamos com Medeiros (2007) acerca do trabalho de docentes do Ensino Superior em universidades com alto prestígio, quando afirma haver clara tendência a privilegiar a pesquisa em detrimento das aulas na graduação. As universidades, de maneira geral, avaliam o profissional docente por meio: do número de artigos publicados, dos projetos aprovados, da captação de recursos para a instituição, do número de teses e dissertações que orienta e avalia, das conferências que profere e dos trabalhos que apresenta em eventos nacionais e internacionais, entre outros. As aulas não têm sido objeto de avaliação sistemática, em termos de qualidade.

O pós-graduando, que se espelha em seus professores e orientadores, segue os mesmos ideais, como se fosse - usando as palavras de Leite (2010) - um "aprendiz de feiticeiro". Porém, considerando que os PPG formam professores para o Ensino Superior, e que conjugar as atividades de pesquisador e professor está no imaginário da maior parte dos estudantes pesquisados, faz-se necessário considerar a complexidade do ato de ensinar e, assim, contribuir para que estes estudantes percebam esta complexidade e busquem conhecimentos que os permitam lidar bem com esta função, caso venham a exercê-la.

Além do que estes estudantes conhecem a respeito da formação didática presente no PPG da UFMG, solicitamos que eles dissertassem sobre o que poderia ser feito para melhorar a qualidade dos PPG em Química, quanto à formação didático-pedagógica. Dos pós-graduandos pesquisados, 76 apresentaram sugestões a respeito desta formação, dois afirmaram que nada precisa ser mudado, e 21 estudantes se abstiveram de responder. A Tabela 2 mostra as sugestões descritas pelos pesquisados.

Ao fornecerem sugestões de atividades que poderiam auxiliar na formação didática, os pós-graduandos demonstram perceber que esta formação é limitada. Porém, algumas delas - cursos rápidos, seminários e oficinas - parecem estar voltadas ao que se tem chamado de modelo pautado na racionalidade técnica (SCHNETZLER; ARAGÃO, 2000). Neste modelo, considera-se que, para ensinar Química, basta saber Química e usar alguns conhecimentos práticos e psicopedagógicos. 
Quadros, A. L. et al.

Tabela 2. Sugestões apresentadas pelos pós-graduandos pesquisados para melhoria do PPG em Química, no que tange à formação didática

\begin{tabular}{lc}
\hline \multicolumn{1}{c}{ Sugestões dos pós-graduandos } & Incidência \\
\hline Inserção de mais disciplinas didáticas na grade curricular & 20 \\
Obrigatoriedade em assumir disciplina da graduação & 16 \\
Obrigatoriedade do Estágio em Docência & 13 \\
Cursos rápidos e práticos ou seminários, oficinas & 8 \\
Oportunidade de assumir disciplinas com assistência dos professores das mesmas & 7 \\
Validar as atividades docentes, na forma de créditos para o curso de Pós-graduação & 4 \\
Aumento do número de vagas para professores substitutos & 4 \\
Aumento do número de bolsas direcionadas à prática pedagógica & 2 \\
Oferta de oportunidade de alunos assumirem aulas dos orientadores & 1 \\
Autorização para estudantes com bolsa lecionarem fora dos limites das instituições federais de & 1 \\
Ensino Superior & 76 \\
Total & 7 \\
\hline
\end{tabular}

Fonte: Elaborado pelos autores.

Outros estudantes mostraram afinidade com tendências desses programas, quando sugerem a obrigatoriedade do Estágio de Docência. Desde 2009, o próprio PPG em Química da UFMG tornou a disciplina Treinamento em Docência em Química obrigatória para todos os doutorandos ingressos a partir dessa data. Talvez a sugestão de mais disciplinas didáticas, feita pelos pesquisados, esteja relacionada ao fato de haver uma única disciplina externa ao Departamento de Química - Didática do Ensino Superior - que pode ser cursada por eles. Porém, esta nem sempre é ministrada por professores com formação em Ensino de Química e/ou Ciências. Neste caso, assim como as disciplinas de Química discutem conteúdo sem transitarem por questões relacionadas ao ensino deste conteúdo, a disciplina de didática pode estar ensinando teorias de ensino e aprendizagem sem transitar pela Química.

A obrigatoriedade e/ou oportunidade em assumir disciplinas foram bastante citadas pelos pesquisados. Certamente, trata-se de uma experiência que dará, aos pós-graduandos, a oportunidade de conhecerem, como professores, a sala de aula de Ensino Superior. Porém, a obrigatoriedade do Estágio em Docência, por si só, não garante uma formação didática pautada em teorias de ensino e aprendizagem.

Alguns dos pesquisados que sugeriram tornar a disciplina de Treinamento em Docência em Química obrigatória consideraram o pouco incentivo dos orientadores para esta atividade. Segundo eles, alguns orientadores julgam que o envolvimento de pós-graduandos com aulas pode prejudicar o andamento da pesquisa.

As demais sugestões feitas pelos pós-graduandos (aumento de vagas para professor substituto, validação de créditos para o curso de pós-graduação e autorização para trabalhar enquanto é bolsista) parecem estar ligadas ao interesse em melhorar o próprio currículo, e não, necessariamente, à formação pedagógica.

Não podemos deixar de fazer uma consideração importante sobre as sugestões oferecidas pelos pós-graduandos. Ela se refere às experiências como professor, seja no Estágio de Docência ou nas substituições em disciplinas e/ou aulas. Qualquer experiência que vise à formação didática, que não se constitua em um processo reflexivo organizado, reforçará a tendência de formar o que já chamamos de aprendizes de feiticeiro. Vários estudos (por exemplo, QUADROS et al., 2005; FONTANA, 2000; CUNHA, 1998) têm apontado para uma 
A formação do professor universitário ...

formação pautada na "imitação" da prática de professores que tiveram e que consideram de sucesso. Porém, este professor "admirado" trabalhou em um contexto diferente e em uma época diferente.

Hoje, as tecnologias de informação e comunicação, sobretudo a internet, propiciam uma dinâmica diferente à sociedade contemporânea. A mudança nas relações e a rapidez com que o conhecimento se transforma trazem consequências para a sala de aula. Além disto, estudos importantes advindos, especialmente, das áreas da psicologia, da sociologia e da filosofia já permitiram adentrar em conhecimentos sobre as formas de aprender, que apontam para mudanças no ensino. É a discussão sobre estas mudanças que esperamos ver permeando as propostas de formação didática para o Ensino Superior.

\section{Percepção sobre a necessidade de formação docente}

Diante das oportunidades oferecidas pelo PPG em Química da UFMG, perguntamos, aos estudantes, se houvesse possibilidade de assumirem uma disciplina durante o curso, quais seriam as condições que eles consideravam importantes para que sua atuação fosse bemsucedida. Para esta questão, 18 se abstiveram e oito respostas foram dadas no sentido de negar esta possibilidade. Destes oito, um afirma que o cenário existente é suficiente para a formação, outro alega que não tem tempo para esta formação, e seis defendem que isto deveria ser programado apenas para aqueles que mostrassem interesse. Para os que consideraram esta possibilidade, alguns destacaram mais de uma condição, totalizando 84 respostas, que estão apresentadas na Tabela 3.

Tabela 3. As condições necessárias para assumir uma disciplina da graduação durante o curso, segundo os pós-graduandos

\begin{tabular}{lc}
\hline \multicolumn{1}{c}{ Respostas dos pós-graduandos } & Incidência \\
\hline Sob orientação dos professores & 28 \\
Recebendo remuneração & 9 \\
Assumindo apenas alguns tópicos das disciplinas & 7 \\
No primeiro ano de doutorado (ao menos um semestre) ou no final do curso & 7 \\
Com carga horária adequada & 6 \\
Após ter feito o treinamento docente ou disciplina didática & 6 \\
Após exame de qualificação & 5 \\
Desde que a aula ministrada conte como crédito no curso & 5 \\
Como professor substituto & 3 \\
Com condições adequadas (explicitadas no texto) & 2 \\
Atuando como estagiário & 2 \\
Contando como experiência profissional & 1 \\
Total & 84
\end{tabular}

Fonte: Elaborado pelos autores.

Ao considerarem a possibilidade de assumirem uma disciplina da graduação durante o curso de pós-graduação, os pesquisados indicam, como condição, a orientação dos professores. Esta condição considera tanto o professor da disciplina quanto professores com formação 
Quadros, A. L. et al.

didática. Parece-nos coerente que estes estudantes se sintam inseguros na função de professor, já que a própria formação não prioriza a formação de professor, e sim a de pesquisador.

Receber remuneração, contar como crédito no curso e como experiência profissional, e atuar como professor substituto são condições apontadas que associamos a um interesse específico, e não apenas com a própria formação docente. Esta é uma discussão antiga, a qual não temos a intenção de abordar. Porém, é preciso considerar que, ao usufruir de instituições públicas por longos anos, o aprendiz poderia, numa certa fase, oferecer algum tipo de retribuição à sociedade. De maneira geral, todos pagam impostos, mas em função do sistema político em que vivemos, apenas alguns podem usufruir das vagas oferecidas nas instituições públicas de ensino.

Outros estudantes mantiveram suas condições na organização temporal, mostrando certa preocupação de que esta função possa vir a atrapalhar o desenvolvimento da pesquisa. Neste item incluímos os pesquisados que sugeriram a atividade para o início ou final do curso ou após o exame de qualificação. Dois outros grupos não consideraram a disciplina como um todo e vincularam esta prática à quantidade de aulas, citando que trabalhariam algum tópico da disciplina ou em uma carga horária adequada.

Dois estudantes relacionaram a disciplina à função de estagiários, e outros seis, que assumiriam a disciplina após terem cursado o Treinamento em Docência em Química. Os dois estudantes que incluímos no grupo de "condições adequadas" já desenvolveram atividades docentes durante o curso, e afirmaram que o tratamento dado aos estagiários é diferenciado, já que, segundo eles, só os professores têm acesso aos equipamentos e artefatos tecnológicos.

Para os estudantes que demonstraram interesse na formação didática, consideramos que isto está atrelado à percepção que têm do mercado de trabalho. Nos últimos anos, impulsionado pelos programas de expansão de vagas nas universidades federais, tem aumentado o número de vagas para professores nestas instituições. Algumas pesquisas (ARROIO; RODRIGUES FILHO; SILVA, 2006; CADORE; FERREIRA, 2004) têm mostrado que poucos egressos dos cursos de pós-graduação são absorvidos pelas indústrias, sendo este número, aproximado, de apenas 25\% dos mestres e $5 \%$ dos doutores.

Os concursos para as instituições federais de ensino avaliam também a didática do candidato, por meio de uma aula. Desta forma, não temos garantido que o interesse demonstrado pelos pesquisados em relação à formação didática esteja vinculado à atenção com a atividade futura que irão desempenhar. Talvez isto seja decorrente de um interesse maior em ser aprovado em concurso público. Porém, mesmo que o interesse seja específico para uma fase da carreira, se o estudante se apropriar de conhecimentos que o permitam ter melhor desempenho em uma prova, provavelmente, os terá ao desempenhar as funções de professor.

O desafio colocado se refere à inserção de atividades que venham a aumentar, nos PPG em Química, a consciência sobre necessidades formativas para atuar como professor. O que falta dentro de um PPG para que haja uma melhor formação de docentes e para que os pós-graduandos vejam esta formação como necessária? Enquanto os PPG estiverem voltados apenas para a formação de pesquisadores em seus campos específicos em detrimento da formação didático-pedagógica de professores, esta última permanecerá a cargo de iniciativas individuais. Sabendo que é fundamental a boa formação do pós-graduando tanto do ponto de vista científico quanto didático-pedagógico, julgamos urgente que sejam pensadas ações conjuntas entre as diversas instituições de Ensino Superior e, também, dos PPG específicos com os PPG em educação. 
A formação do professor universitário ...

\section{Conclusão}

A formação docente, apesar de ser considerada necessária pelos estudantes de PPG em Química, parece estar mais vinculada à construção de currículos (quanto maior o tempo de experiência didática, maior a pontuação adquirida em concursos públicos) e ao preparo para os concursos públicos - os quais, certamente, os atuais estudantes de PPG enfrentarão assim que obtiverem seus títulos de mestre e/ou doutores - do que à formação didático-pedagógica para atuarem como professores do Ensino Superior.

Provavelmente, esta é uma concepção criada dentro da própria instituição de Ensino Superior, que coloca disciplinas didáticas em todos os seus cursos de formação de professores, mas nega a necessidade deste saber quando se trata de seus próprios professores. Como consequência, os professores universitários, que sempre desempenharam sua função docente sem que uma formação didática fosse considerada necessária, acabam por auxiliar na construção da concepção de que a formação do professor de Ensino Superior precisa ser pautada, exclusivamente, pelo domínio de conhecimentos específicos da área na qual atuará.

O professor universitário, ao ser sutilmente pressionado a desenvolver pesquisa e a publicar seus resultados, dedica grande parte do seu tempo/espaço de trabalho ao desenvolvimento da pesquisa, e menos à melhoria do ensino. Os estudantes que adentram nesse mundo, e que algumas vezes passam pela Iniciação Científica, Mestrado e Doutorado, acabam por se tornarem "aprendizes de feiticeiros", influenciados pelo ambiente em que estão inseridos e pela atuação dos professores que admiram.

Os PPG em Química poderiam dedicar maior atenção em conhecer as expectativas dos estudantes quanto à formação docente, e, assim, promover ações que atendam estas necessidades. Dentro do possível, estas ações poderiam ser articuladas com programas ou professores da área de educação, caso estes se disponham a tal.

Programas de Iniciação a Docência já desenvolvidos em cursos de graduação da UFMG realizam atividades de planejamento conjunto de aulas, de desenvolvimento destas aulas (na maioria das vezes, gravadas em vídeo), de análise/avaliação das mesmas, com novos planejamentos. Isto acontece em um processo de reflexão sobre a prática planejada, que se mostra importante para o futuro professor. Talvez os PPG pudessem incorporar algumas destas experiências e proporcionar uma formação pedagógica pautada no planejamento, na ação, na reflexão sobre a ação e na ação sobre a reflexão na ação.

\section{Agradecimentos}

Ao CNPQ e à Capes, pelo apoio financeiro concedido. 
Quadros, A. L. et al.

\section{Referências}

ARROIO, A.; RODRIGUES FILHO, U. P.; SILVA, A. B. F. da. A formação do pósgraduando em química para a docência em nível superior. Química Nova, São Paulo, v. 29, n. 6, p. 1387-1392, 2006

ARROIO, A. et al. A prática docente na formação do pós-graduando em química. Química Nova, São Paulo, v. 31, n. 7, p. 1888-1891, 2008.

BRASIL. Lei n. ${ }^{\circ} 9.394$ de 20 de dezembro de 1996. Estabelece as diretrizes e bases da educação nacional. Diário Oficial \{da\} República Federativa do Brasil, Brasília, 23 dez. 1996. Disponível em: < http://portal.mec.gov.br/arquivos/pdf/ldb.pdf>. Acesso em: 13 jul. 2009.

CADORE, S.; FERREIRA, V. F. O papel da pós-graduação na formação do químico. Química Nova, São Paulo, v. 27, p. 181-181, 2004.

CUNHA, M. I. O professor universitário na transição dos paradigmas. 2. ed. Araraquara: JM, 1998.

FEITOSA, J. P. A. Construindo o estágio de docência da pós-graduação em química. Química Nova, São Paulo, v. 25, n. 1, p. 153-158, 2002.

FELICÍSSIMO, A. M. P. et al. Prática de ensino de química no $3^{\circ}$ grau - uma experiência no curso de pós-graduação. Química Nova, São Paulo, v. 14, n. 2, p. 122-124, 1991.

FONTANA, R. A. C. Como nos tornamos professoras? 2. ed. Belo Horizonte: Autêntica, 2000.

LEITE, D. O futuro do hoje e os estudantes. In: DALBEN, A. et al. Convergências e tensões no campo da formação e trabalho docente: ensino superior. Belo Horizonte: Autêntica, 2010. p. 553-572. (Coleção didática e prática de ensino).

MALDANER, O. A. A pesquisa como perspectiva de formação continuada do professor de química. Química Nova, São Paulo, v. 22, n. 2, p. 289-292, 1999.

MEDEIROS, A. M. S. A docência no ensino superior: dilemas contemporâneos. Revista Faced, Salvador, n. 12, p. 71-87, 2007.

PACHANE, G. G. Formação pedagógica de pós-graduandos para a atuação docente no ensino superior: a experiência da Unicamp. Educere et Educare: revista de educação, Cascavel, v. 2, n. 4, p. 219-233, 2007.

QUADROS, A. L. et al. Os professores que tivemos e a formação da nossa identidade como docentes: um encontro com nossa memória. Ensaio: pesquisa em educação em ciências, Belo Horizonte, v. 7, n. 1, p. 1-8, 2005.

Percepção dos pós-graduandos em química da UFMG sobre a própria formação docente. Química Nova, São Paulo, v. 34, n 5, p. 893-898, 2011. 
SCHÖN, D. A. Formar professores como profissionais reflexivos. In: NÓVOA, A. (Org.). Os professores e sua formação. Lisboa: Dom Quixote, 1992. p. 77-91.

SCHNETZLER, R. P.; ARAGÃO, R. M. R. (Org.). Ensino de ciências: fundamentos e abordagens. Piracicaba: Capes; Unimep, 2000.

UNIVERSIDADE FEDERAL DE MINAS GERAIS. Programa de Pós-Graduação em Química. Apresentação. Disponível em: < http://www.qui.ufmg.br/pg/programa/ objetivo/>. Acesso em: 11 mar. 2010.

ZANON, D. A. V.; OLIVEIRA, J. R. S.; QUEIROZ, S. L. O “saber" e o "saber fazer" necessários à atividade docente no ensino superior: visões de estudantes de pós-graduação em química. Ensaio: pesquisa em educação em ciências, Belo Horizonte, v. 11, n. 1, p. 1-20, 2009. 